\title{
Intestinal flora during the first months of life: new perspectives
}

\author{
C. A. Edwards* and A. M. Parrett \\ Department of Human Nutrition, Glasgow University, Yorkhill Hospitals, Glasgow G3 8SJ, UK
}

\begin{abstract}
Increasing awareness that the human intestinal flora is a major factor in health and disease has led to different strategies to manipulate the flora to promote health. The complex microflora of the adult is difficult to change in the long term. There is greater impact of diet on the infant microflora. Manipulation of the flora particularly with probiotics has shown promising results in the prevention and treatment of diarrhoea and allergy. Before attempting to change the flora of the infant population in general, a greater understanding of the gut bacterial colonisation process is required. The critical stages of gut colonisation are after birth and during weaning. Lactic acid bacteria dominate the flora of the breast-fed infant. The formula-fed infant has a more diverse flora. The faeces of the breast-fed infant contain mainly acetic and lactic acid whereas the formula fed-infant has mainly acetic and propionic acid. Butyric acid is not a significant component in either group. The formula-fed infant also has higher faecal ammonia and other potentially harmful bacterial products. The composition of the microflora diversifies shortly before and particularly after weaning. The flora of the formula-fed infant develops more quickly than that of the breast-fed infant. Before embarking on any strategy to change the flora, the following questions should be considered: Should we retain a breast-fed style flora with limited ability to ferment complex carbohydrates? Can pro- and prebiotics achieve a flora with adult characteristics but with more lactic acid bacteria in weaned infants? Are there any health risks associated with such manipulations of the flora?
\end{abstract}

Infants: Gut microflora: Breast-feeding: Weaning

\section{Introduction}

The bacterial microflora of the human intestine is complex and numerous. The bacteria ferment unabsorbed carbohydrate to short-chain fatty acids (SCFA) which have many health benefits related to heart disease and cancer prevention. However, they have also been implicated in the aetiology of colonic disorders such as colitis and cancer (Onoue et al. 1997; Campieri \& Gionchetti, 2001).

There has been increasing scientific, medical and commercial interest in the intestinal microflora. This began with the awareness of the actions of the SCFA, was increased by the resurgence of the health benefits of lactic acid bacteria (probiotics) and is maintained by the emergence of food products containing probiotics and prebiotics (materials which increase the growth of probiotic bacteria).

This increase in awareness has also been fuelled by the development of new techniques for identifying and investigating the flora. New molecular techniques based on bacterial RNA and DNA have rekindled the mystery of the gut flora (Vaughan et al. 2000). These methods have shown that a significant proportion of bacterial
DNA in human faeces is not accounted for by known and culturable species (Sghir et al. 2000).

The current understanding of the importance of the gut microflora has led to different strategies to manipulate the bacterial populations to promote health. These include changes to the diet, inclusion of unabsorbable carbohydrates and ingestion of live bacteria with potential health benefits (probiotics). However, the complex microflora of the adult human is difficult to manipulate in the long term. The flora is made up of at least 400 different species in the dominant flora (Moore et al. 1978; Tannock, 2000) which create a stable ecosystem resistant to new bacterial species.

There is a greater impact of diet on the intestinal microflora of the human infant. Several groups have explored the interactions between diet, the intestinal bacteria, diarrhoea (Howie et al. 1990; Pathmakanthan et al. 2000) and allergy (Wold, 1998; Bjorksten et al. 1999; Ouwehand et al. 2001). Manipulation of the gut flora of the infant has shown promising results (Saavadra et al. 1994; Arvola et al. 1999; Isolauri, 2001; Kalliomaki et al. 2001). Optimising the microflora of the infant may also have long-term benefits if the flora of the adult

\footnotetext{
Abbreviation: SCFA, short-chain fatty acids.

* Corresponding author: Dr C. Edwards, fax +44 141201 9275, email cae1n@clinmed.gla.ac.uk
} 
is determined by events occurring in this critical period of gut colonisation. However, before the flora of infants in the general population is altered, for example by the addition of probiotics or carbohydrates that promote their growth (prebiotics) to normal infant formula or weaning foods, it must be clear what is intended and what the long-term consequences might be. To predict the long-term effects, a much greater understanding is required of the bacterial colonisation process and the metabolic activity of the flora.

\section{Bacterial colonisation in the newborn}

The critical stages of gut colonisation are in the days after birth and during weaning (Fig. 1). At birth the gut is sterile and as the infant is exposed to bacteria in its environment, the birth canal, maternal faecal bacteria and other sources (Tannock et al. 1990; Zetterstrom et al. 1994), the colonisation process begins. In the first months of life, diet has a crucial influence on the bacteria and their metabolism. Several studies, using conventional culture techniques, have shown that the flora of the breast-fed infant is dominated by bifidobacteria and lactobacilli, whereas the flora of the formula-fed infant contains more bacteroides, clostridia and Enterobacteriaceae (Balmer \& Wharton, 1989; Fuller, 1991). Some studies have not seen this difference (Simhon et al. 1982; Lundequist et al. 1985) which may be due to changes in obstetric practice. However, the differences have been confirmed by new molecular techniques (Harmsen et al. 2000; Martin et al. 2000). Most infants in the UK are fed both breast and formula milk during their first months of life due either to an inability of the mother to produce sufficient milk, or cessation of breast-feeding by the mother due to a return to work or for other reasons. Very little is known of the bacterial flora of infants fed a mixture of breast and formula milk.

The mechanisms for the difference in the flora of infants fed human milk and modern formula are numerous and difficult to reproduce despite great efforts taken by infant formula manufacturers to mimic human milk as closely as possible. Immunological factors such as secretory immunoglobulin A and lysozyme in human milk prevents the growth of some bacteria. The lower faecal $\mathrm{pH}$ of breast-fed infants (Bullen \& Willis, 1971) may promote bacteria such as the lactobacilli and bifidobacteria, which are more tolerant of acid. Fe-related factors may also be important. The iron content of human milk is low (about $0.5 \mathrm{mg} / \mathrm{l}$; Bullen et al. 1972), but the Fe present has a high bioavailibility (Siimes et al. 1979; Calvo et al. 1992). This is increased by the presence of lactoferrin, which aids $\mathrm{Fe}$ absorption and binds any unabsorbed $\mathrm{Fe}$ making it unavailable to bacteria in the colon. Bifidobacteria and lactobacilli do not need $\mathrm{Fe}$ in contrast to bacteroides and enterobacteria (Archibald, 1983). Fe added to infant formula has been found to increase the growth of clostridia and enterococci (Balmer \& Wharton, 1991). However, Fe-free formula, although promoting a flora more like that of the breast-fed infant, still did not produce a flora dominated by lactic acid bacteria. The effects of added lactoferrin have been inconsistent perhaps related to the use of bovine rather than human lactoferrin (Balmer et al. 1989a). Increasing the whey to casein ratio in the protein fraction of the milk, however, does promote a more breast-fed style flora although there are still major differences (Balmer et al. 1989b; Roberts et al. 1992).

There are several bifidogenic factors in human milk and these might be considered natural prebiotics. They include non-absorbable oligosaccharides (3-6g/l in mature milk; Kunz \& Rudolff, 1993). The amount of oligosaccharides in colostrum is even higher. These oligosaccharides mainly consist of a lactose core substituted with $\mathrm{N}$-acetyl glucosamine, galactose, fucose and sialic acid resulting in over 100 different compounds (Kunz \& Rudolff, 1993). Recently infant food products, which

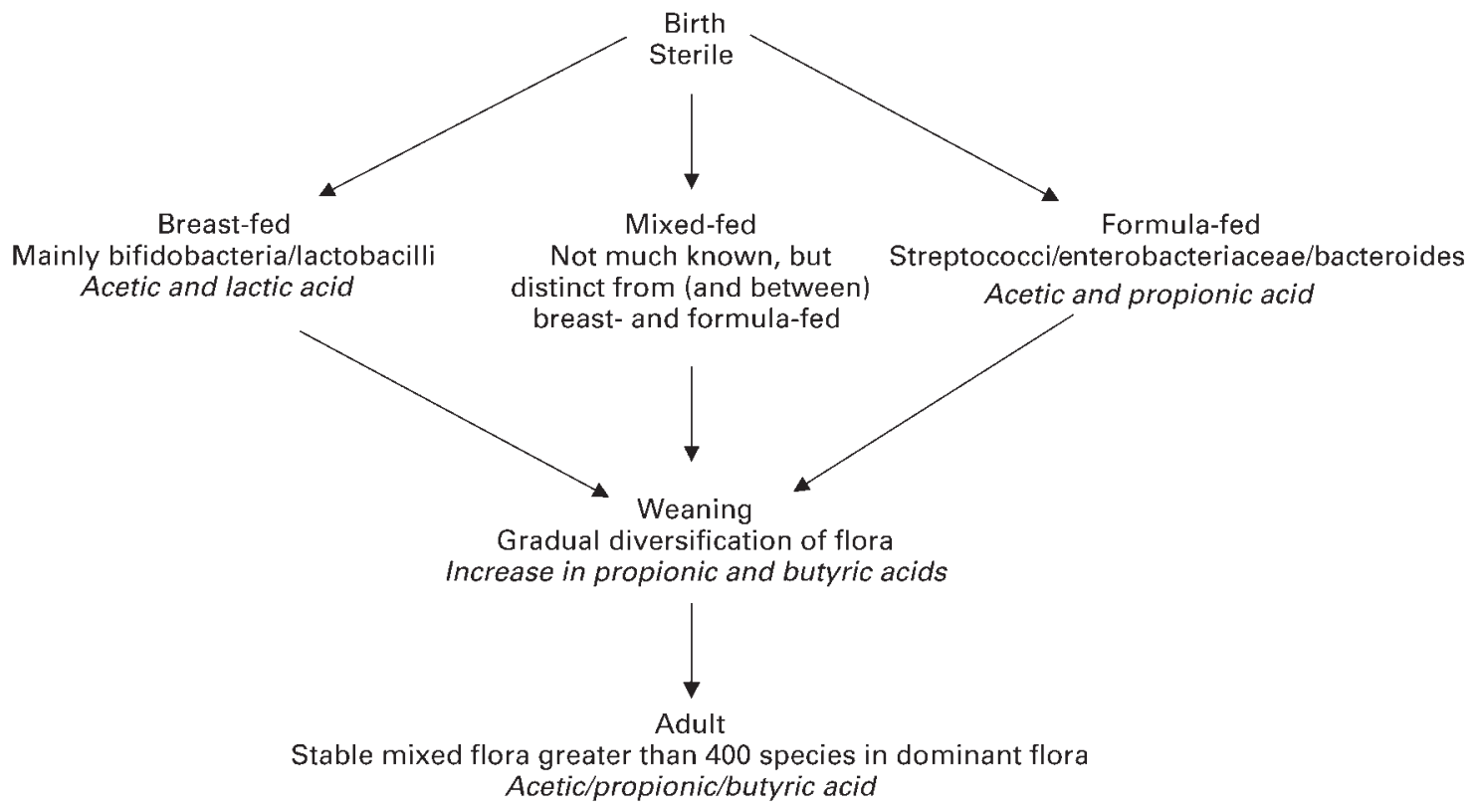

Fig. 1. A scheme of the development of the intestinal microflora in humans. 
include oligosaccharides and are aimed at specific groups of infants with intestinal symptoms, have been launched in Europe. However, at present there is little published information on their impact on the faecal flora. Human milk also contains nucleotides (Gil et al. 1986; Balmer et al. 1994) and gangliosides (Rueda et al. 1998) which when added to formula milk have in some studies been shown to increase colonisation by bifidobacteria.

\section{Bacterial metabolism}

The metabolic activity of the adult microflora is equivalent in size and diversity to that of the liver but is often involved in reversing actions of the liver. For example, the liver conjugates toxic compounds with sugars or amino acids to make them safer; in the colon these conjugations are broken down and the toxins and other compounds reactivated. Many of the complex bacterial activities are a function of bacteroides, clostridia and other bacteria present in only low concentrations in the infant gut.

\section{Short-chain fatty acids}

The fermentation of carbohydrate is a major function of the intestinal flora. Carbohydrate provides most of the energy for the bacteria but the SCFA produced provide the host with an alternative energy source (Livesey, 1990), a mechanism to absorb water in the large intestine (Ruppin et al. 1980 ) and an inhibitory agent against pathogens (Fay \& Faries, 1975).

The profile of SCFA in the faeces of infants differs substantially from that in adult faeces. In meconium, SCFA are very low, about $10 \%$ of adult values, increasing in the first four days of life. SCFA concentrations in the breast-fed infant are still low and increase significantly in the first year of life (Parrett et al. 2000). The molar proportions of the individual SCFA are also very different. In adults the major faecal SCFA are acetic, propionic and n-butyric acid in the proportions 57:22:21 (Szylit \& Andrieux, 1993). Acetic and lactic acids dominate the SCFA profile of the breast-fed infant. There is little or no propionic or butyric acid (Edwards et al. 1994), whereas the faeces of the formula-fed infant is dominated by acetic acid and propionic acid with a higher proportion of butyric acid than breast-fed infants but still much less than adult faeces. There is generally no lactic acid. Butyric acid is believed to be the major fuel for the colonocytes (Roediger, 1982) and thought to be essential for colonic health. Butyrate has also been shown to have antineoplastic properties by stimulating apoptosis (programmed cell death) of colonic cells (Hague \& Paraskeva, 1995), differentiation of cancer cell lines in vitro (Augeron \& Laboisse, 1984), and inhibiting other important stages in cancer development (Candido et al. 1978; Borenfreud et al. 1980). The lack of butyric acid in infant faeces may mean that butyrate is not critical for the infant colon or that most of the butyrate necessary is absorbed or utilised by the colonic mucosa before it reaches the faeces. However, studies of fermentation in vitro, using infant faeces, also show very low butyric acid production (Parrett et al.
1997). A high production of propionic acid and its ratio to acetic acid may help promote healthy plasma lipid levels (Venter et al. 1990; Wolever et al. 1991, 1996; Berggren et al. 1996). How this relates to the low propionic acid levels in the breast-fed infant is unclear.

As stated earlier, infants in many Western societies are fed a mixture of breast milk and formula milk. Some are fed breast and formula milk at different feeds and infants who begin with breast milk often are given formula milk within a few days or weeks after birth. In the UK, the number of mothers who are breast-feeding at discharge from hospital is substantially more than the number $1-6$ weeks later (White et al. 1992). The impact of the introduction of formula milk to an initially breast-fed infant is not well studied. There is a belief that one bottle of formula milk will convert the flora of the breast-fed infant to that of an infant fed exclusively on formula milk. Bullen et al. (1977) reported that faecal $\mathrm{pH}$ was less acidic in mixedfed infants than those exclusively breast-fed, but was still lower than in formula-fed infants. In a recent longitudinal study of nineteen mixed-fed infants, the SCFA in faeces indicated a distinct pattern of fermentation from either breast-fed or formula-fed infants before and during the weaning process (Parrett et al. 2001).

The simplicity of the infant flora limits its fermentation capacity for complex carbohydrates. When the fermentation capacity of the faecal flora from breast-fed and formula-fed infants for simple and complex carbohydrates was compared with that of adult faecal flora using a simple in vitro model, the infant flora from both groups of infants was much less able to ferment complex carbohydrates (Parrett \& Edwards, 1997a) than the adult flora. The total SCFA produced by the infants' microflora was not affected by the type of milk fed but the proportions of individual SCFA (acetate, propionate, lactic) in the culture supernatant reflected the different patterns of SCFA seen in infant faeces (Parrett \& Edwards, 1997a).

\section{Other bacterial activities}

There are many colonic bacterial activities, not associated with carbohydrate fermentation, some of which may have undesirable effects in the human colon. Most of these activities are associated with the adult colonic flora and do not develop until later in the first or second year of life.

Midtvedt et al. (1988) have studied a range of bacterial activities in early life. Mucin degradation ability was not established before 3 months of age. This ability was first seen in many children later in the first year of life and in all children by the second year (Midtvedt et al. 1994). The ability to deconjugate bile acids was already present at 1 month (Jonsson et al. 1995) whereas the ability to convert cholesterol to coprostanol developed in the second half of the first year and was delayed by breastfeeding (Midtvedt \& Midtvedt, 1993). At 6 months urobilinogen production was very low with most infants gaining this activity between 11 and 21 months (Norin et al. 1985).

The metabolites of protein degradation such as ammonia, cresol and paracresol have been associated with harmful effects in the colonic mucosa and systemically 
after absorption. Phenol and cresol had growth-depressing effects in young pigs (Yokoyama et al. 1982). Before weaning formula-fed infants had higher faecal urease activity (Gronlund et al. 1999) and faecal ammonia (Heavey et al. 2000) than breast-fed infants. Phenol and cresol levels were also higher (Heavey et al. 2000).

The enzymes $\beta$-glucuronidase and $\beta$-glucosidase may be involved in the activation of carcinogens and other toxins in the large intestine. The activity levels of these enzymes are low in the breast-fed infant before weaning but are increased in formula-fed infants possibly reflecting the more diverse flora. In a recent study $\beta$-glucuronidase activity was significantly higher in formula-fed than in breast-fed infants (Gronlund et al. 1999; Heavey et al. 2000), $\beta$-glucosidase was also higher in the formula-fed infants but this did not achieve statistical significance. The level of all these bacterial activities increased substantially after weaning as the flora diversified (Heavey et al. 2000).

\section{Effect of weaning}

The next critical stage after birth in the development of the flora occurs during the slow process of weaning (Fig. 1). There are several factors which change during weaning, including the addition of non-milk foods to the diet and the continued development of intestinal function. The amount of dietary carbohydrate which enters the colon in the infant depends on the digestive and absorptive ability of the small intestine (Christian et al. 1999). The intestine of the neonate is immature with low salivary amylase and low pancreatic function. Salivary amylase reaches adult levels between six months and one year (Rossiter et al. 1974). Pancreatic amylase is very low (1.6\% of the adult level at birth) until four months and does not increase until the end of the first year, with mature levels only reached by the fifth year (Gillard et al. 1989). Mucosal enzymes such as glucoamylase may compensate for this and amylase and lipase in breast milk may aid digestion and absorption. Pancreatic sensitivity to cholecystokinin and secretin (Zoppi et al. 1972; Lebenthal \& Lee, 1980) is much reduced in infancy and transport of sugars across the mucosa may also be much lower than in the adult gut (Younoszai, 1974; McNeish et al. 1983). In neonates, lactose may be a major substrate for the colonic microflora. Kien et al. (1992) estimated that up to $74 \%$ of lactose might be metabolised in the large intestine of premature babies but other studies suggest that lactase activity is already present at adult levels in the small intestine of most term infants. However, the very acid nature of the breast-fed infant stool and the high SCFA and lactate content would suggest that a substantial amount of rapidly fermentable carbohydrate is escaping digestion in the small intestine.

As weaning begins, infants are exposed for the first time to many different complex carbohydrates. A significant proportion of the starch will escape digestion because of the lack of chewing ability and immature pancreatic exocrine function in these young infants. This will enter the colon along with any dietary fibre. We have shown that significant amounts of starch are detectable in the faeces of children up to the age of 3 years (Verity \& Edwards,
1994; Parrett et al. 2000). This starch will have escaped both digestion and fermentation. If colonic fermentation capacity develops sufficiently rapidly, the colonic salvage of energy from unabsorbed complex carbohydrates may contribute significantly to daily energy needs in these infants. In adults the energy gained from fermentation of complex carbohydrate is estimated as $8.36 \mathrm{~kJ} / \mathrm{g}$ (Livesey, 1990). As weaning progresses, both intestinal function and fermentation capacity mature and the amount of faecal starch peaks in early weaning and then decreases (Parrett et al. 2000). However in some breast-fed infants the level is still significant at 1 year. In another study using in vitro incubation methods, infants during early weaning appeared to have a greater and faster capacity for fermenting starch than adults, perhaps reflecting the greater likelihood of starch entering the colon of the infants (Christian et al. 2000). In the developing world, where starchy foods such as cassava with low digestibility are eaten by pre-school children, faecal starch is high and may be a cause of high faecal energy losses (Hamaker et al. 1991). However, in the developed world the amount of starch excreted is too small to have any impact on energy losses (Parrett, 2001).

The concentrations and profiles of SCFA in the faeces of human infants change as weaning progresses (Midtvedt \& Midtvedt, 1992). The rate of change is related to initial feeding practice. In the breast-fed infant there is a gradual increase in total SCFA concentration with a decrease in lactic acid production, an increase in acetic and propionic acid and by late weaning a gradual increase in butyric acid production. In the formula-fed infant the change is less profound, mainly because of the more mature SCFA production before weaning. The proportion of propionic acid decreases as butyric acid increases (Parrett, 2001).

The ability of the colonic flora of the breast-fed infant to ferment complex carbohydrates appears to develop more slowly than that of the formula-fed infant. This is understandable in the light of the greater diversity of species in the formula-fed infant colon and the greater populations of Gram-negative anaerobes. In a cross-sectional in vitro study of fermentation capacity of infants at different stages of weaning (Parrett et al. 1997; Fig. 2), it was found that before weaning breast-fed infants could ferment the simple sugars lactose and glucose well. However, raftilose, a fructo-oligosaccharide from inulin, was less well fermented and the complex carbohydrate soya polysaccharide was hardly fermented at all. In early weaning (one month after the introduction of solid foods) the ability to ferment raftilose increased but the ability to ferment complex carbohydrates did not increase until late weaning (seven months to one year). The differences in fermentation capacity of the formula-fed infants at the different stages of weaning were not significant indicating a faster maturation of their colonic flora (Parrett \& Edwards, 1997b). In a more recent longitudinal study, breast-fed infants had a similar slow development of the capacity to ferment complex carbohydrates although there was much variation in individual infants (Parrett, 2001). Pectin was more readily fermented than other complex carbohydrates such as resistant starch and guar gum at each stage of weaning. 


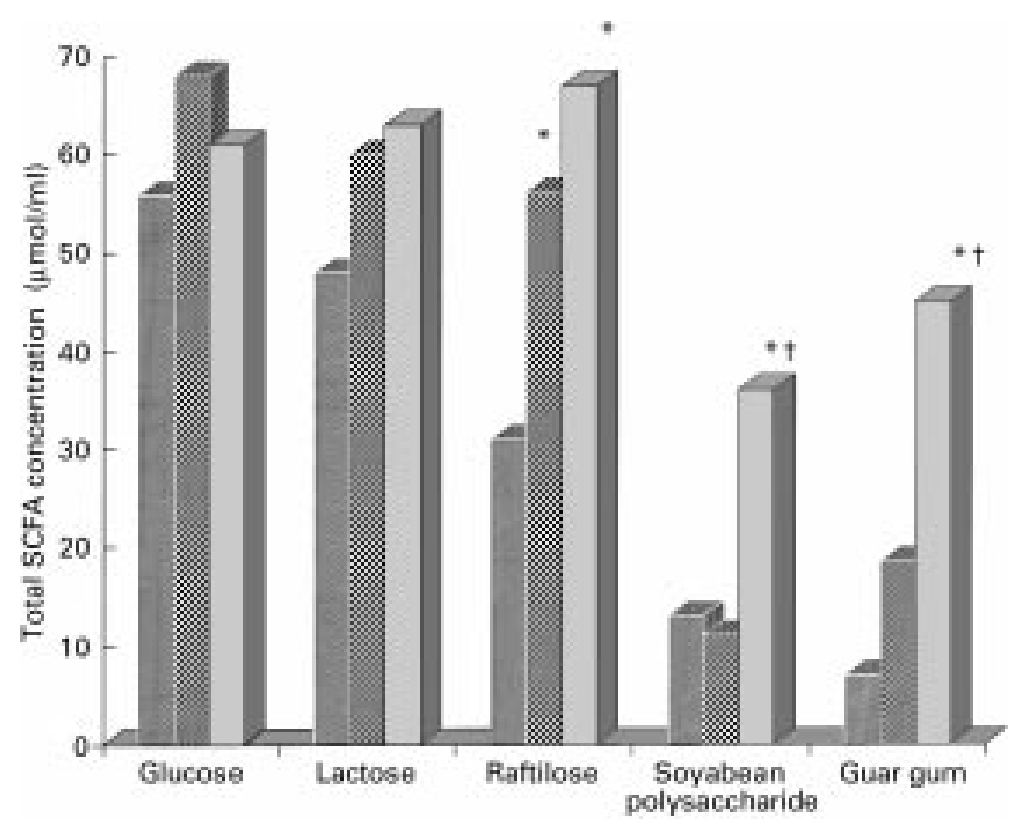

Fig. 2. Short-chain fatty acid (SCFA) production from different carbohydrates by faecal bacteria of breast-fed infants at different stages of weaning in vitro. (1) before weaning; (»), early weaning, $(\square$ late weaning; *Significantly different compared with before weaning; ${ }^{\top}$ significantly different compared with early weaning. (From Parrett \& Edwards, 1997a,b).

The impact of a weaning diet is likely to persist into adulthood. The amount and type of dietary fibre in the weaning diet of rats influenced their fermentation capacity for these fibres and consequent effects on stool output when the same fibres were fed to adult rats (Armstrong et al. 1992). More SCFA were present in faeces when pectin was fed to adult rats for a month if the rats had been fed this dietary fibre during weaning than if they had been weaned onto a diet containing other dietary fibre. Moreover, rats produced more SCFA from a low fibre diet as adults if they were fed dietary fibre at weaning. In a study in South Africa, faecal bacteria from children, under the age of three, from Soweto township produced more butyric acid from different carbohydrates in vitro than the bacteria from white children in Potchefstroom. This may have been a result of a higher intake of resistant starch in their diet at weaning (Edwards et al. 1998).

As the gut is developing throughout the first year of life, it is important to consider if the changes in the intestinal flora occur as a result of weaning or just at the time that weaning occurs. Recent longitudinal studies of human infants using rRNA probes show that the bacterial flora diversifies with greater dominance of bacteroides and clostridia groups even before weaning in both breast-fed and formula-fed infants (Martin et al. 2000). The effects of weaning therefore need to be studied carefully, taking this into account.

\section{Conclusion}

The flora of the infant develops slowly during the first year of life. The flora of the breast-fed infant has been shown to be beneficial for the infant reducing the incidence of diarrhoea. It is possible that manipulation of the flora, by use of food products containing prebiotics, probiotics and synbiotics (a mixture of pro- and prebiotics), may allow promotion of a more beneficial flora which could reduce gastrointestinal problems, allergy and other debilitating conditions, as well as potentially helping to prevent chronic adult diseases such as heart disease and colon cancer. However, there have been very few good studies of the likely impact of these food products on the infant flora and its metabolism. In particular, long-term effects are unknown. At this important time in the infant's development, we must be clear of our intentions. Should we change the microflora of the infants during weaning? This may have greater implications than just increasing the numbers of some bacterial species. If we try and maintain a breastfed style flora for as long as possible we may limit the ability of the weaning infant to cope with the complex carbohydrates and dietary fibres in their diet. The most sensible manipulation may be to encourage the development of fermentation capacity for complex carbohydrates but at the same time increase the dominance of the lactic acid bacteria. This would promote the production of butyric acid, which may become more important in the older child despite being low in infancy. The levels of lactic acid bacteria could then be promoted through childhood and into adulthood by dietary means. However, much detailed research is needed. At present most research is aimed at infants with specific gastrointestinal and allergy problems. We need to know much more about the normal population and 'normal' colonic function. 


\section{References}

Archibald FS (1983) Lactobacillus plantorum - an organism not requiring iron. FEMS Microbiology Letters 19, 29-32.

Armstrong EF, Eastwood MA, Edwards CA, Brydon WG \& MacIntyre CCA (1992) The effect of weaning diet on the subsequent colonic metabolism of dietary fibre in the adult rat. British Journal of Nutrition 68, 741-751.

Arvola T, Laiho K, Torkkeli S, Mykkanene H, Salminene S, Maunula L \& Isolauri E (1999) Prophylactic Lactobacillus GG reduces antibiotic associated diarrhoea in children with respiratory infections a randomised study. Pediatrics 104, e64.

Augeron C \& Laboisse CL (1984) Emergence of permanently differentiated cell clones of human colonic cancer cell line in culture after treatment with sodium butyrate. Cancer Research 44, 3961-3969.

Balmer SE, Harvey CS \& Wharton BA (1994) Diet and faecal flora in the newborn: nucleotides. Archives of Disease and Childhood 70, F137-F140.

Balmer SE, Scott PH \& Wharton BA (1989a) Diet and infant faecal flora: lactoferrin. Archives of Disease in Childhood 64, $1685-1690$.

Balmer SE, Scott PH \& Wharton BA (1989b) Diet and faecal flora of the newborn; casein and whey protein. Archives of Disease in Childhood 64, 1678-1684.

Balmer SE \& Wharton BA (1989) Diet and faecal flora of the new born: breast milk and infant formula. Archives of Disease in Childhood 64, 1672-1677.

Balmer SE \& Wharton BA (1991) Diet and faecal flora in the newborn: iron. Archives of Disease in Childhood 66, 1390-1394.

Berggren AM, Margareta E, Nyman GL, Ludquist I \& Bjorck IME (1996) Influence of orally and rectally administered propionate on cholesterol and glucose metabolism in obese rats. British Journal of Nutrition 76, 287-294.

Bjorksten B, Naaber P, Sepp E \& Mikelsaar M (1999) The intestinal microflora in allergic Estonian and Swedish 2-year-old children. Clinical and Experimental Allergy 29, 342-346.

Borenfreud E, Schmid E, Bendich A \& Franke WS (1980) Constitutive aggregates of intermediate-sized filaments of the vimentin and cytokeratin type in cultured hepatoma cells and their dispersal by butyrate. Experimental Cell Research 127, 215-235.

Bullen CL, Tearle PV \& Stewart MG (1977) The effects of humanised milks and supplemented breast milk on the faecal flora of infants. Journal of Medical Microbiology 10, 403-413.

Bullen CL \& Willis AT (1971) Resistance of the breast-fed infant to gastroenteritis. British Medical Journal 3, 338-343.

Bullen JJ, Rodgers HJ \& Leigh L (1972) Iron binding proteins in milk and resistance to $E$ coli infections in infants. British Medical Journal 1, 69-75.

Calvo EB, Galindo AC \& Aspres NB (1992) Iron status in exclusively breast-fed infants. Pediatrics 90, 375-379.

Campieri M \& Gionchetti P (2001) Bacteria as the cause of ulcerative colitis. Gut 48, 132-135.

Candido EP, Reeves R \& Davie JR (1978) Sodium butyrate inhibits histone deacetylase in cells. Cell 14, 105-113.

Christian MT, Edwards CA \& Weaver LT (1999) Starch digestion in infancy. Journal of Pediatric Gastroenterology and Nutrition 29, 116-124.

Christian MT, Edwards CA, Preston T, Johnson LA, Varley R \& Weaver LT (2000) Patterns of colonic starch fermentation from infancy to adulthood. Proceedings of the Nutrition Society 59, 36A.

Edwards CA, Hepburn IC, Segal I, Hassan H, Vorster E, Oosthuizen W \& Kruger S (1998) Colonic fermentation capacity in young children from South African populations of low and high cancer risk. In Functional Properties of Nondigestible Carbohydrates, pp. 222-224 [F Guillon and R Amado, editors]. Brussels: EU Commission DGX11.

Edwards CA, Parrett AM, Balmer SE \& Wharton BA (1994) Faecal short chain fatty acids in breast-fed and formula-fed babies. Acta Paediatrica Scandinavica 83, 459-462.

Fay JP \& Faries RN (1975) The inhibitory action of fatty acids on the growth of E coli. Journal of General Microbiology 91, 233-240.

Fuller R (1991) Factors affecting the composition of the intestinal microflora of the human infant. In Nutritional Needs of the 6-12 Month Infant, pp. 121-130 [WC Heird, editor]. New York: Raven Press.

Gil A, Corral E, Maritnez A \& Molina JA (1986) Effects of nucelotides on the microbial pattern of faeces of at term newborn infants. Journal of Clinical Nutrition and Gastroenterology 1, 34-38.

Gillard BK, Simbala JA \& Goodglick L (1989) Reference intervals for isoenzymes in serum and plasma of infants and children. Clinical Chemistry 29, 1119-1123.

Gronlund MM, Salimen S, Mykkanen H, Kero P \& Lahtonen OP (1999) Development of intestinal bacterial enzymes in infants: relationship to mode of delivery and feeding. Acta Pathology Microbial Immunology Scandinavica 107, 655-660.

Hague A \& Paraskeva C (1995) The short-chain fatty acid butyrate induces apoptosis in colorectal tumour cell lines. European Journal of Cancer Prevention 4, 359-364.

Hamaker BR, Rivera K, Morales E \& Graham GG (1991) Effects of dietary fiber and starch on faecal composition in preschool children consuming maize amaranth or cassava flours. Journal of Pediatric Gastroenterology and Nutrition 13, 59-66.

Harmsen HJM, Wibleboer-Veloo ACM, Raangs GC, Wagendorp AA, Klijn N, Bindels JG \& Wellings GW (2000) Analysis of intestinal flora development in breast-fed and formula-fed infants using molecular identification and detection methods. Journal of Pediatric Gastroenterology and Nutrition 30, 61-67.

Heavey PM, McBain AJ, Rumney CJ, Rowland IR, Savage SAH \& Edwards CA (2000) Metabolic properties of faecal samples from breast fed and formula fed babies. Proceedings of the Nutrition Society 59, 62A.

Howie PW, Forsyth JS, Ogston SA, Clark A \& Florey CD (1990) Protective effect of breast-feeding against infection. British Medical Journal 300, 11-16.

Isolauri E (2001) Probiotics in the prevention and treatment of allergic disease. Pediatric Allergy and Immunology 12, Suppl. $14,56-59$.

Jonsson G, Midtvedt AC, Norman A \& Midtvedt T (1995) Intestinal microbial bile acid transformation in healthy children. Journal of Pediatric Gastroenterology and Nutrition 20, 394-402.

Kalliomaki M, Kirjavainen P, Eerola E, Kero P, Salminen S \& Isolauri E (2001) Distinct patterns of neonatal gut microflora in infants in whom atopy was and was not developing. Journal of Allergy and Clinical Immunology 107, 129-134.

Kien CL, Kepner J, Grotjohn K, Ault K \& McClean RE (1992) Stable isotope method for estimating colonic acetate production in premature infants. Gastroenterology $\mathbf{1 0 2}$, $1458-1466$.

Kunz C \& Rudolff S (1993) Biological functions of oligosaccharides in human milk. Acta Paediatrica Scandinavica 82, 902-912.

Lebenthal E \& Lee DC (1980) Development of functional response in human exocrine pancreas. Pediatrics 66, $556-560$. 
Livesey G (1990) Energy values of unavailable carbohydrates and diets. American Journal of Clinical Nutrition 51, 617-637.

Lundequist B, Nord CE \& Windberg J (1985) The composition of the microflora in breast fed and bottle fed infants from birth to eight weeks. Acta Paediatrica Scandinavica 74, 45-51.

McNeish AS, Mayne A, Ducker DA \& Hughes CA (1983) Development of D-glucose absorption in the perinatal period. Journal of Pediatric Gastroenterology and Nutrition 2, S222-S226.

Martin F, Savage SAH, Parrett AM, Gramet G, Dore J \& Edwards CA (2000) Investigation of bacterial colonisation of the colon in breast-fed infants using novel techniques. Proceedings of the Nutrition Society 59, 64A.

Midtvedt AC, Carlstedt-Duke B \& Midtvedt $T$ (1994) The establishment of mucin degrading microflora during the first two years of life. Journal of Pediatric Gastroenterology and Nutrition 18, 321-326.

Midtvedt AC, Carlstedt-Duke B, Norin KE, Saxerholt H \& Midtvedt T (1988) Development of five metabolic activities associated with the intestinal microflora of healthy infants. Journal of Pediatric Gastroenterology and Nutrition 7, $559-567$.

Midtvedt AC \& Midtvedt T (1992) Production of short chain fatty acids by the intestinal microflora during the first two years of human life. Journal of Pediatric Gastroenterology and Nutrition 18, 321-326.

Midtvedt AC \& Midtvedt T (1993) Conversion of cholesterol to coprostanol by the intestinal microflora during the first two years of human life. Journal of Pediatric Gastroenterology and Nutrition 17, 161-168.

Moore WEC, Cato EP \& Holdeman LV (1978) Some current concepts in intestinal bacteriology. American Journal of Clinical Nutrition 31, 533-542.

Norin KE, Gustafsson BE, Lindblad BS \& Midtvedt T (1985) The establishment of some microflora associated biochemical characteristics in faeces from children during the first years of life. Acta Paediatrica Scandinavica 74, 207-212.

Onoue M, Kado S, Sakaitani Y, Uchida K \& Morotomi M (1997) Specific species of intestinal bacteria influence the induction of abeherrant crypt foci by 1,2 dimethylhydrazine in rats. Cancer Letters 113, 179-186.

Ouwehand AC, Isolauri E, He F, Hashimoto H, Benno Y \& Salminen S (2001) Differences in Bifidobacterium flora composition in allergic healthy infants. Journal of Allergy and Clinical Immunology 108, 144-145.

Parrett AM (2001) Development of colonic fermentation in early life. PhD Thesis, Glasgow University.

Parrett AM \& Edwards CA (1997a) In vitro fermentation of carbohydrate by breast-fed and formula fed infants. Archives of Disease in Childhood 76, 249-253.

Parrett AM \& Edwards CA (1997b) The effect of weaning on fermentation capacity in formula fed infants. Proceedings of the Nutrition Society 56, 309A.

Parrett AM, Farley K, Fletcher A \& Edwards CA (2001) Comparison of faecal short chain fatty acids in breast-fed, formula-fed and mixed fed neonates. Proceedings of the Nutrition Society 60, 48A.

Parrett AM, Khanna S \& Edwards CA (2000) Excretion of faecal starch and fat in breast fed and formula fed infants during weaning. Proceedings of the Nutrition Society 59, 64A.

Parrett AM, Lokerse E \& Edwards CA (1997) Colonic fermentation in vitro: development during weaning in breast fed infants is slower for complex carbohydrates than for sugars. American Journal of Clinical Nutrition 65, 927-933.

Pathmakanthan S, Meance S \& Edwards CA (2000) Probiotics: a review of human studies to date and methodological approaches. Microbial Ecology in Health and Disease 12, Suppl. 2, 10-30.
Roberts AK, Chierrici R, Sawatzki G, Hill MJ, Volpato S \& Vigi V (1992) Supplementation of an adapted formula with bovine lactoferrin 1. Effect on the infant faecal flora. Acta Paediatrica Scandinavica 81, 119-124.

Roediger WEW (1982) Utilization of nutrients by isolated epithelial cells of the rat colon. Gastroenterology 83, 424-429.

Rossiter MA, Barrownman JA, Dand A \& Wharton BA (1974) Amylase content of mixed saliva in children. Acta Paediatrica Scandinavica 63, 389-392.

Rueda R, Sabatel JL, Maldonado J, Moilna-Font JA \& Gil A (1998) Addition of gangliosides to an adapted milk formula modifies levels of faecal microflora in preterm newborn infants. Journal of Pediatrics 133, 90-94.

Ruppin H, Bar-meir S, Soergel KH, Wood CM \& Schmitt MG (1980) Absorption of SCFA by the colon. Gastroenterology 78, $1500-1507$.

Saavadra JM, Bauman NA, Oung I, Pernan JA \& Yolken RH (1994) Feeding of Bifidobacterium bifidum and Streptococcus thermophilus to infants in hospital for prevention of diarrhoea and shedding of rotavirus. Lancet 344, 1046-1049.

Sghir A, Gramet G, Suau A, Rochet V, Pochart P \& Dore J (2000) Quantification of bacterial groups within human faecal flora by oligonucleotide probe hybridisation. Applied and Environmental Microbiology 66, 2263-2266.

Siimes MA, Vuori E \& Kuitenen P (1979) Breast milk iron: a decline in concentration during the course of lactation. Acta Paediatrica Scandinavica 68, 29-31.

Simhon A, Douglas JR, Drasar BS \& Soothill JH (1982) Effect of feeding on infants' faecal flora. Archives of Disease in Childhood 57, 54-58.

Szylit O \& Andrieux C (1993) Physiological and pathophysiological effects of carbohydrate fermentation. World Review of Nutrition and Diet 74, 88-122.

Tannock GW (2000) Molecular assessment of the intestinal microflora. American Journal of Clinical Nutrition 73, s401-s414.

Tannock GW, Fuller R, Smith SL \& Hall MA (1990) Plasmid profiling of members of the family enterobacteriaceae, lactobacilli and bifidobacteria to study the transmission of bacteria from mother to infant. Journal of Clinical Microbiology 28, $1225-1228$.

Vaughan EE, Schhut F, Heilig HGHJ, Zoetendal EG, de Vos WM \& Akkermans ADL (2000) A molecular view of the intestinal ecosystem. Current Issues in Intestinal Microbiology 1, 1-12.

Venter CS, Vorster HH \& Cummings JH (1990) Effects of dietary propionate on carbohydrate and lipid metabolism in human volunteers. American Journal of Gastroenterology 85, 549-553.

Verity K \& Edwards CA (1994) Resistant starch in young children. Proceedings of the Nutrition Society 53, 105A.

White A, Freeth S \& O'Brien M (1992) Office of Population Census and Surveys Infant Feeding Study 1990. London: HM Stationery Office.

Wold AE (1998) The hygiene hypothesis revised: is the rising frequency of allergy due to changes in the intestinal flora? Allergy 53, Suppl. 46, 20-25.

Wolever TMS, Fernandes J \& Venketeshwer Rao A (1996) Serum acetate:propionate ratio is related to serum cholesterol in men but not women. Journal of Nutrition 126, 2790-2797.

Wolever TMS, Spadafora P \& Eshius H (1991) Interaction between colonic acetate and propionate in humans. American Journal of Clinical Nutrition 53, 681-687.

Yokoyama MT, Tabori C, Miller ER \& Hogberg GS (1982) The effects of antibiotics in weaning pigs measuring growth and excretions of volatile phenolic and aromatic metabolites. American Journal of Clinical Nutrition 35, 1417-1422.

Younoszai MK (1974) Jejunal absorption of hexose in infants and adults. Journal of Pediatrics 85, 446-448. 
Zetterstrom R, Bennet R \& Nord KE (1994) Early infant feeding and microecology of the gut. Acta Pediatrica Japonica 36, $562-571$.
Zoppi G, Andreotti P, Pajna-Ferrarra F, Njai DM \& Gaburro D (1972) Exocrine pancreas function in premature and full term neonates. Pediatric Research 6, 880-886. 